PERES \& BERTUOL, v(5), n5, p. 850 - 856, 2012.

Revista Eletrônica em Gestão, Educação e Tecnologia Ambiental

REGET/UFSM (e-ISSN: 2236-1170).

\title{
RECICLAGEM DE BATERIAS DE ÍONS DE LÍTIO DE APARELHOS CELULARES: RECUPERAÇÃO DO SOLVENTE ORGÂNICO DO ELETRÓLITO ATRAVÉS DA ADSORÇÃO EM CARVÃO ATIVADO
}

\author{
Bruno Andrzeyevski Peres', Daniel Assumpção Bertuol² \\ ${ }^{1}$ Graduando de Engenharia Química, UFSM, Autor, email: bap.ufsm@gmail.com \\ ${ }^{2}$ Prof.Dr., DEQ/CT/UFSM, Orientador, email: dbertuol@gmail.com
}

\section{RESUMO}

A reciclagem de equipamentos eletrônicos vem se tornando fundamental devido à escassez de recursos naturais associada ao crescente desenvolvimento de novas tecnologias para estes equipamentos os quais se tornam obsoletos de forma cada vez mais rápida. A maioria dos aparelhos celulares fabricados é equipada com baterias de íons de lítio. Essas baterias são compostas por um cátodo, um anodo e um separador entre eles que estão embebidos em um solvente orgânico, com sais de lítio, que age como eletrólito. O solvente orgânico é composto por uma mistura de carbonatos. Os estudos sobre a reciclagem das baterias Li-lon visam geralmente à recuperação dos metais presentes em sua composição, como o cobre. Mas até agora existe pouca informação disponível sobre a recuperação do solvente orgânico presente nas baterias Li-lon. Solvente esse que é tóxico e poluente. O objetivo deste trabalho foi quantificar o solvente da bateria e evitar a emissão deste a partir da adsorção em carvão ativado. Como resultado, obtevese uma quantidade considerável de voláteis nas baterias, de 9 a $12 \%$ do peso total destas. A adsorção do solvente foi feita em um equipamento com carvão ativado. No carvão ficaram adsorvidos aproximadamente 27,38 \% do solvente da bateria. Essa adsorção mostrou-se eficaz até um determinado ponto, onde não se consegue mais adsorver o solvente porque possivelmente o carvão chegou a sua capacidade máxima de adsorção. Outro motivo do baixo rendimento de adsorção pode ser devido às reações do solvente com a água presente no ar no momento da abertura da bateria.

Palavras-chave: Baterias Li-Ion, Reciclagem, Solvente Orgânico

\section{ABSTRACT}

The recycling of electronic equipment has become essential due to the scarcity of natural resources associated with the increasing development of new technologies for these devices which become obsolete in an increasingly faster. Most mobile phones are manufactured equipped with lithium-ion batteries. These batteries are composed of a cathode, an anode and a separator between them that is embedded in an organic solvent with lithium salts, which acts as an electrolyte. The organic solvent comprises a mixture of carbonates. Studies on the recycling of LiIon batteries generally aim to recover the metals present in their composition, such as copper. But so far there is little information available about the recovery of organic solvent present in the LiIon batteries. That this solvent is toxic and polluting. The objective of this study was to quantify the solvent and prevent the emission of solvent from the activated carbon adsorption. As a result, we obtained a considerable amount of volatiles in the batteries, 9 to $12 \%$ of the total weight of these. The adsorption of solvent was made in an equipment with activated carbon. Adsorbed on 


\section{Revista Eletrônica em Gestão, Educação e Tecnologia Ambiental REGET/UFSM (e-ISSN: 2236-1170).}

activated carbon were approximately $27.38 \%$ of the solvent from the battery. This process seemed to be effective to a point where one can no longer adsorb the solvent for possibly carbon reached its maximum adsorption capacity. Another reason for the low yield of the adsorption may be due to reactions of the solvent with water in the air in the moment of the opening of the battery.

Keywords: Li-Ion Batteries, Recycling, Organic Solvent

\section{INTRODUÇÃO}

Devido ao crescente número de baterias recarregáveis de Íons de Lítio descartadas, usadas em equipamentos eletrônicos como aparelhos celulares, associados aos riscos ao meio ambiente, fazem-se necessário estudar métodos eficientes para reciclagem de baterias Li-lon. Exemplo disso é que existem mais de cinco bilhões de telefones móveis no mundo, na sua maioria com baterias Li-Ion, segundo a empresa de análise da Indústria Móvel: Wireless Intelligence. ${ }^{1}$

A tecnologia aplicada nos equipamentos eletrônicos tem se desenvolvido muito rapidamente, reduzindo a vida útil desses aparelhos e ocasionando um aumento no descarte desses produtos. ${ }^{2}$

Baterias de Íons de Lítio são compostas por um cátodo e um ânodo e há um separador embebido em um solvente orgânico com sais de lítio, que agem como o eletrólito.

Os eletrólitos mais utilizados são compostos por sais de lítio dissolvidos em carbonatos orgânicos juntamente com alguns aditivos para melhorar sua estabilidade e aumentar a segurança. A presença dos sais de lítio nestas baterias se deve ao processo de condução iônica. São esses sais, dissolvidos no eletrólito, que promovem o transporte de íons do cátodo para o ânodo (carga) e do ânodo para o cátodo (descarga). É essencial que esses sais, tenham como principais características: elevada condutividade iônica e estabilidade térmica e química. ${ }^{3}$

O solvente tem a função de auxiliar na condução de íons e diminuir a formação da interface sólido-líquido (SEI) que acontece no processo de carga da bateria. Quando o potencial se encontra numa faixa entre $0,7-1,5 \mathrm{~V}$, os solventes orgânicos e os produtos da decomposição do sal de lítio sofrem redução no eletrodo negativo. O resultado dessa redução é uma película fina (SEI) formada sobre o mesmo. A formação dessa camada sobre o eletrodo negativo consome íons de lítio. Sendo assim, sua formação resulta na perda de capacidade das baterias de íons de lítio, uma vez que esse processo de redução é irreversível. ${ }^{4}$

O solvente orgânico é composto por carbonatos, principalmente o etileno carbonato (EC) e o propileno carbonato (PC), pois estes apresentam grande condutividade iônica e boa estabilidade térmica. O EC, a temperatura ambiente, encontra-se em estado sólido, pois apresenta ponto de congelamento em $39^{\circ} \mathrm{C}$. Já o $\mathrm{PC}$ tem um ponto de congelamento de $-48^{\circ} \mathrm{C}$. A mistura de EC e PC provoca um aumento natural da estabilidade térmica do eletrólito. $\mathrm{O}$ etil-metil-carbonato (EMC) também apresenta boa estabilidade térmica. A mistura de EC e EMC favorece a formação de um eletrólito com alta condutividade iônica em temperaturas mais baixas. Em temperaturas mais negativas, a mistura EC-EMC apresenta uma queda no rendimento pela redução da condutividade. Adicionando PC a essa mistura, percebe-se uma melhora nesse desempenho.

O melhor solvente então é uma mistura contendo Etileno Carbonato, Propileno Carbonato e Etil-metil-Carbonato. Outros carbonatos também utilizados são Di-metil-Carbonato e Di-etilCarbonato. As vantagens dessa mistura de solventes são a baixa viscosidade, que amplia a condutividade do eletrólito e o baixo ponto de congelamento, que promove uma melhora no desempenho das baterias em baixas temperaturas. ${ }^{5}$ 


\section{Revista Eletrônica em Gestão, Educação e Tecnologia Ambiental REGET/UFSM (e-ISSN: 2236-1170).}

Existem grandes problemas no descarte de baterias Li-Ion, um destes problemas está relacionado com os solventes orgânicos, que são tóxicos e inflamáveis (baixo ponto de fulgor), e junto com sais de lítio, como LiPF6 e LiClO4, em contato com o ar, reagem e formam gases extremamente poluentes e podem provocar explosões. Existe também a possibilidade de contaminação do solo e da água, resultantes da lixiviação da bateria pela água da chuva ou pelo chorume gerado pela decomposição da matéria orgânica dos lixos domésticos. ${ }^{6}$

Em estudos sobre reciclagem de baterias Li-Ion, existe pouca referência sobre a recuperação ou tratamento do solvente orgânico, sendo este evaporado antes de processos de reciclagem, geralmente visando à recuperação de metais da bateria. Em processamentos mecânicos para reciclagem de baterias, moagem destas por exemplo, os solventes são vaporizados e contaminam o ambiente.

\section{METODOLOGIA}

Quantificação do solvente: primeiramente foram feitos testes para determinar a quantidade de voláteis presentes em baterias de Li-lon, através da secagem da bateria já aberta.

Foram utilizadas 5 baterias de 3 diferentes modelos. Sendo três baterias da marca A, de mesmo modelo, uma bateria da marca B e uma bateria da marca C. Baterias essas de um lote de aparelhos de celulares descartados disponibilizado por assistências técnicas de celulares de Santa Maria - RS.

Para abertura da bateria, primeiramente, com o auxílio de um voltímetro, verificou-se $\mathrm{s}$ existência de carga na bateria a ser analisada. Isto foi feito para evitar que ocorresse um curtocircuito. Depois a bateria foi aberta com o auxílio de um alicate de corte e foi pesada.

A bateria foi então colocada em uma estufa para secagem do solvente a aproximadamente $60^{\circ} \mathrm{C}$, durante 24 horas. Depois de seca foi feito um balanço de massa para se determinar a quantidade de voláteis na bateria a partir da massa final e inicial.

Testes de Adsorção: através de consultas à literatura, chegou-se a conclusão de que um método com rendimento satisfatório, para a recuperação do solvente das baterias de Li-lon seria a adsorção deste, em fase gasosa, em uma coluna de adsorção com leito fixo de carvão ativado.

Para fazer esta recuperação, antes foram feitos testes utilizando compostos com características semelhantes aos carbonatos presentes no solvente.

Foram utilizados nos testes iniciais substancias como o Hexano $(86,18 \mathrm{~g} / \mathrm{mol})$ que tem peso molecular próximo do Etileno Carbonato $(88,06 \mathrm{~g} / \mathrm{mol})$. Outro composto que foi utilizado é a acetona, por ser um composto orgânico muito utilizado como solvente e por ser inflamável, e também por ter uma ligação dupla carbono-oxigênio bem como os carbonatos presentes no solvente.

Para estes testes foram utilizados rotaevaporador composto de um balão de vidro em banho de óleo a $60{ }^{\circ} \mathrm{C}$, para fazer a evaporação da substancia a ser adsorvido. Também uma coluna de adsorção com carvão ativado de 6 a $10 \mathrm{~mm}$ de diâmetro de partícula, como adsorvente, e uma bomba de sucção utilizada para fazer o hexano passar pelo carvão ativado como pode ser observado na Figura 1: 


\section{Revista Eletrônica em Gestão, Educação e Tecnologia Ambiental} REGET/UFSM (e-ISSN: 2236-1170).

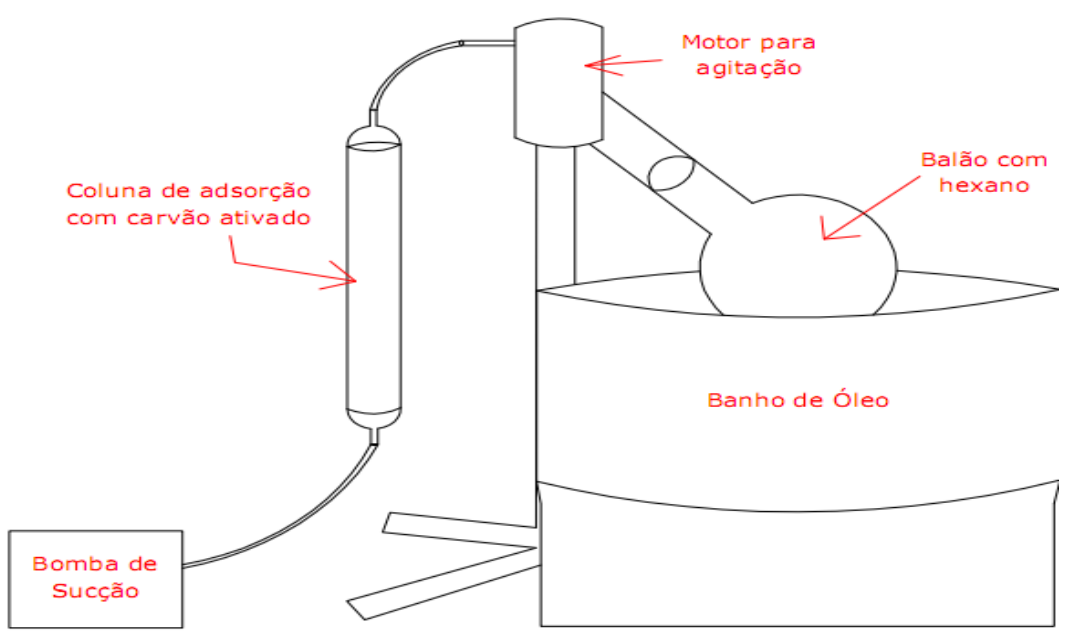

Figura 1 - Equipamento para adsorção

Adsorção do solvente orgânico das baterias Li-Ion: após os testes iniciais de adsorção com hexano e acetona, foi feita uma tentativa de adsorção do solvente das baterias Li-lon. A bateria (marca A) foi aberta na capela com o auxilio de um alicate de corte e foram separadas suas partes internas (Figura 2), como mostra a figura abaixo:

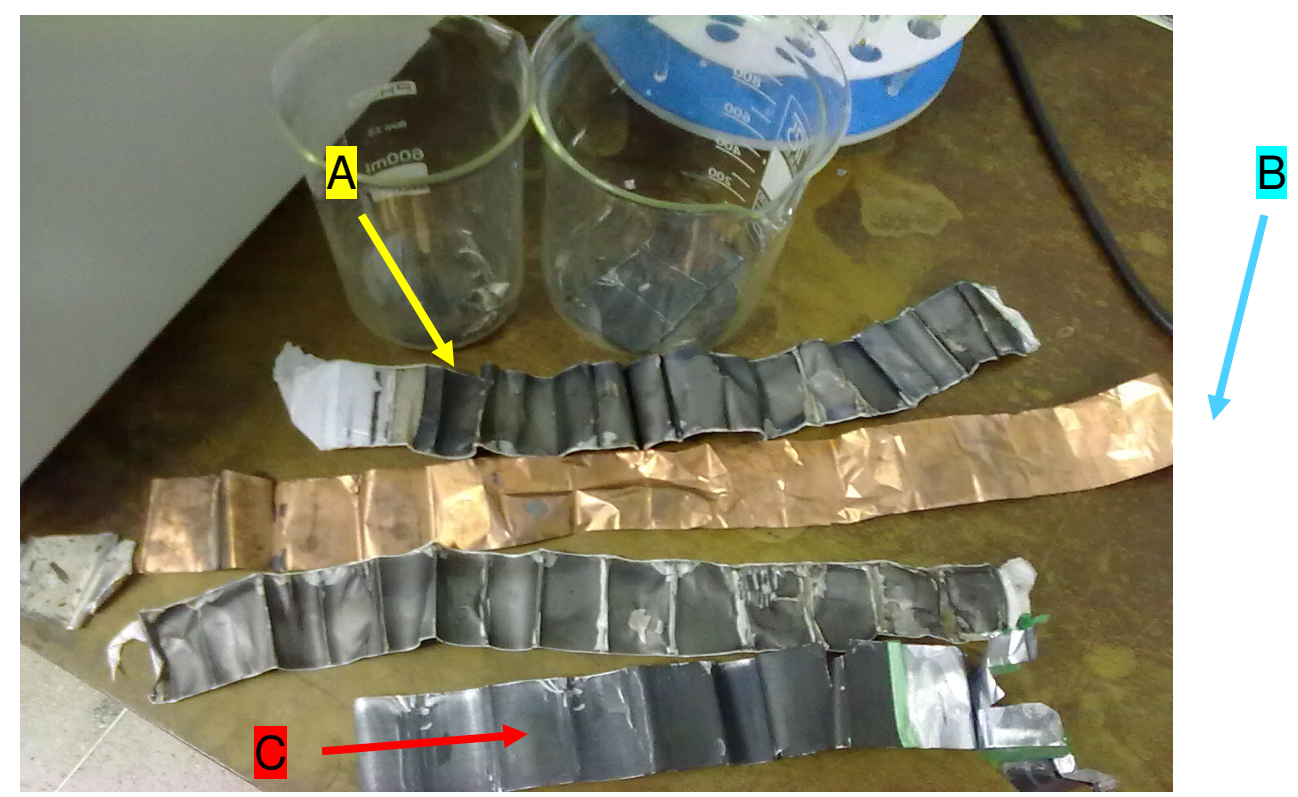

Figura 2 - A - Separador, B - Ânodo, C - Cátodo

Ao abrir a bateria, foi possível visualizar cada um dos seus constituintes. Cátodo e ânodo encontram-se, enrolados e separados pelo separador sob forma de uma bobina e submersos em um líquido viscoso (eletrólito). São compostos por uma folha de alumínio e cobre, respectivamente, nas quais são colados seus materiais ativos na forma de pó.

Após aberta, a bateria foi colocada no balão do esquema da Figura 1 para que o solvente fosse evaporado a fim de se adsorver no carvão ativado da coluna de adsorção. 


\section{Revista Eletrônica em Gestão, Educação e Tecnologia Ambiental REGET/UFSM (e-ISSN: 2236-1170).}

O banho de óleo foi colocado a aproximadamente $60^{\circ} \mathrm{C}$, e a cada cinco minutos a coluna de adsorção era pesada.

\section{RESULTADOS E DISCUSSÃO}

\section{Quantificação do solvente}

Para determinação da quantidade de solvente nas baterias Li-lon, foram feitos testes com cinco baterias de celular de três diferentes marcas. Primeiro foram pesadas as baterias ainda fechadas. Depois as baterias foram abertas e colocadas na estufa para evaporar o solvente. Após 24 horas foram retiradas da estufa e foram novamente pesadas. Fazendo um balanço de massa entre a massa inicial e a final, obteve-se como resultados a quantidade de solvente orgânico evaporado para cada bateria:

Tabela 1 - Quantidade de solvente orgânico nas baterias

\begin{tabular}{|c|c|c|c|}
\hline Baterias & $\begin{array}{c}\text { Massa baterias fechadas } \\
\mathbf{( g )}\end{array}$ & Massa baterias secas (g) & $\begin{array}{c}\text { Solvente Orgânico na } \\
\text { bateria (\% do peso total } \\
\text { da bateria) }\end{array}$ \\
\hline Marca A - 1 & 21,8855 & 19,6346 & 10,28 \\
\hline Marca A - 2 & 19,9232 & 18,0938 & 9,08 \\
\hline Marca A - 3 & 23,0253 & 20,6311 & 10,34 \\
\hline Marca B - 1 & 20,0252 & 17,6754 & 11,73 \\
\hline Marca C - 1 & 16,2381 & 14,7631 & 9,08 \\
\hline
\end{tabular}

Os resultados levam a uma quantidade considerável de solvente orgânico presente nas baterias Li-Ion.

\section{Testes de Adsorção}

Primeiramente foi utilizado hexano devido a ser um composto orgânico e ter peso molecular próximo do Etileno Carbonato. Foram colocados no balão, para ser evaporado e adsorvido. A massa de hexano utilizada foi de $1,55 \mathrm{~g}$ de hexano.

A coluna foi pesada antes de iniciar o teste $(277,86 \mathrm{~g})$. A bomba de vácuo foi ligada a fim de forçar o hexano a passar pela coluna. Após a evaporação total do hexano do balão a coluna foi novamente pesada chegando ao resultado da quantidade de hexano adsorvida no carvão ativado:

Tabela 2 - Porcentagem de hexano adsorvido em carvão ativado

\begin{tabular}{|c|c|c|}
\hline Peso da coluna de adsorção antes & Peso da coluna de adsorção depois & Hexano adsorvido \\
\hline $277,86 \mathrm{~g}$ & $279,32 \mathrm{~g}$ & $94,19 \%$ \\
\hline
\end{tabular}

Foram feitos também testes com acetona devida sua ligação dupla carbono-oxigênio que também há nos carbonatos da mistura do solvente. A massa de acetona utilizada foi de 1,67 g.

Os resultados de adsorção de acetona foram os seguintes:

Tabela 3 - Porcentagem de acetona adsorvida em carvão ativado

\begin{tabular}{|c|c|c|}
\hline Peso da coluna de adsorção antes & Peso da coluna de adsorção depois & Acetona adsorvida \\
\hline $275,58 \mathrm{~g}$ & $276,82 \mathrm{~g}$ & $74,11 \%$ \\
\hline
\end{tabular}

Com os resultados do teste, esperava-se uma boa adsorção do solvente da bateria em carvão ativado. 


\section{Revista Eletrônica em Gestão, Educação e Tecnologia Ambiental \\ REGET/UFSM (e-ISSN: 2236-1170).}

\section{Adsorção do solvente orgânico das baterias Li-Ion}

Primeiro a coluna de adsorção com carvão ativado foi pesada, apresentando a massa inicial de $275,61 \mathrm{~g}$.

A bateria (marca A) foi colocada no balão, a bomba de vácuo foi ligada e o banho de óleo foi colocado a $90{ }^{\circ} \mathrm{C}$ para começar a evaporação e adsorção gás-sólido do solvente. A cada cinco minutos a coluna de adsorção foi pesada, chegando então nos seguintes resultados:

Tabela 4 - Pesagem da coluna de adsorção

\begin{tabular}{|c|c|}
\hline Tempo (min.) & Massa da coluna (g) \\
\hline 5 & 275,73 \\
\hline 10 & 275,81 \\
\hline 15 & 275,86 \\
\hline 20 & 275,91 \\
\hline 25 & $\mathbf{2 7 5 , 9 9}$ \\
\hline 30 & 275,99 \\
\hline 35 & 275,95 \\
\hline 40 & 275,88 \\
\hline
\end{tabular}

Percebe-se com a Tabela 6, que até 25-30 minutos houve adsorção do solvente no carvão ativado. Isso pode se comprovar com o aumento do peso da coluna de adsorção. Após meia-hora de adsorção houve uma redução da massa da coluna, o que significa que o carvão já estava saturado e não poderia mais adsorver o solvente e então a bomba começou a puxar solvente.

Com os resultados mostrados na Tabela 6 , tem-se uma adsorção de $0,38 \mathrm{~g}$ de solvente da bateria em carvão ativado.

A partir dos resultados obtidos na quantificação do solvente nas baterias Li-lon, se espera que em uma bateria da marca A tenha aproximadamente $9,90 \%$ de solvente da massa total da bateria.

A bateria utilizada era da marca A com massa de 14,12 g (1,39 g de solvente), já aberta e sem a carcaça de metal. Apenas $\mathbf{2 7 , 3 4} \%(0,38 \mathrm{~g})$ ficaram adsorvidos no carvão ativado.

A mistura de carbonatos que forma o solvente das baterias Li-lon reage rapidamente com a umidade do ar. Na abertura das baterias, pode-se sentir o odor característico da formação de produtos a partir das reações do solvente com água. Esses produtos da reação são perdidos no momento da abertura, e isso pode explicar o fato de ter resultado em um rendimento baixo de adsorção.

Outra explicação possível seria o fato do carvão utilizado na coluna de adsorção ser insuficiente para adsorver a quantidade de solvente presente na bateria, ou seja, a saturação do carvão ocorreu muito antes de todo o solvente ter evaporado do balão.

\section{CONCLUSÕES}

Experimentalmente, pode-se verificar que a quantidade de solvente orgânico presente em uma bateria de Li-Ion é considerável já que corresponde de 9 a $12 \%$ do peso total da bateria. Logo, existe a necessidade de se estudar alguma forma de diminuir a emissão deste solvente a fim 


\section{Revista Eletrônica em Gestão, Educação e Tecnologia Ambiental REGET/UFSM (e-ISSN: 2236-1170).}

de gerar menos gases poluentes na atmosfera já que, devido ao uso e descarte rápido de baterias Li-Ion, isso venha a se tornar um problema recorrente na questão ambiental.

Os testes realizados, tiveram como resultado que a adsorção realmente é um método eficiente na armazenagem de compostos com características parecidas com a mistura de carbonatos do solvente orgânico das baterias Li-Ion.

Apesar dos resultados de adsorção do solvente orgânico não ter um rendimento tão bom quanto se esperava (apenas $27,34 \%$ adsorvido de solvente), já é um resultado considerável, já que quase um terço deste solvente estará deixando de poluir o ambiente. O mínimo de solvente adsorvido já tem um impacto favorável muito grande quanto ao fator ambiental, já que se estará evitando a emissão de gases tóxicos e inflamáveis no ambiente.

Os resultados indicam a necessidade de aumento da quantidade de carvão na coluna de adsorção, no entanto a técnica parece ser viável em função dos ótimos resultados obtidos com hexano.

Posteriormente poderá se realizar um estudo sobre a reutilização deste solvente no eletrólito das baterias Li-lon ou na recuperação dos compostos do solvente, resultando assim em possíveis benefícios econômicos.

\section{REFERENCIAS BIBLIOGRÁFICAS}

1- GSM World. Disponível na Internet: http://gsmworld.com/newsroom/press-releases/2010/5265.htm. Acesso em 30 de Maio de 2011

2- EPBA. EUROPEAN PORTABLE BATTERY ASSOCIATION, 2008 - EPBA INICIATIVES. Disponível na Internet: http://www.epbaeurope.net/epbainit.html

3- NAZRI, G. A. PISTOIA; G. LITHIUM BATTERIES: SCIENCE AND TECHNOLOGY . p. 509-527.

4- VAN SHALKWIJK, W. A.; SCROSATI, B. ADVANCES IN LITHIUM- ION BATTERIES. Kluwer Academic Publishers, Estados Unidos, p. 1-79; 135-251, 2002.

5- ZHANG, S.S.; JOW, T. R.; AMINE, K.; HENRIKSEN, G. L. LiPF6-EC-EMC - ELECTROLYTE FOR LI-ION BATTERIES. Journal of Power Sources, v.107. n. 1, p. 18-23, 2002.

6- LINDEN, D.; REDDY, T. B. HANDBOOK OF BATTERIES, McGraw-Hill Handbooks, capítulos 34-35, 2008.

GEANKOPLIS, C. J. PROCESOS DE TRANSPORTE Y OPERACIONES UNITARIAS, 3a Ed. Compañía Editorial Continental, S.A, CECSA. México, p.773-784, 1998. 